\title{
ALGUNAS PRECISIONES ACERCA DEL CONTRACTUALISMO DE MARSILIO DE PADUA*
}

\author{
Julio A. Castello Dubra**
}

\begin{abstract}
RESUMEN - El trabajo pone en cuestión la pertinencia de la atribución de una concepción contractualista de estilo moderno a Marsilio de $\mathrm{Pa}$ dua. El análisis de los principales textos del Defensor pacis no muestra la afirmación de un hipotético estado no social del hombre, ni un fundamento exclusivamente voluntarista o racionalista de la sociedad política, ni una fundamentación de la legitimidad del poder político en la figura de un contrato efectuado por individuos autónomos que precedan - temporal o lógicamente - a la constitución de la sociedad política.
\end{abstract}

\begin{abstract}
This article discusses whether it is pertinent to attribute to Marsilius of Padua a contractual conception as it is understood today. The analysis of the main texts of his Defensor pacis never exhibits the affirmation of an hypothetic unsocial condition of mankind nor an exclusively voluntaristic or rationalistic basis of the political society. There also we don't perceive nothing established about the legitimacy of the political power characterized as a contract made by free individuals preceding logically or in time the formation of the political society.
\end{abstract}

Marsilio de Padua es sin duda el pensador político medieval más señalado como precedente de ciertas ideas políticas modernas. Ha sido visto como un precursor de la teoría del Estado moderno, ${ }^{1}$ un defensor de los principios del republicanismo y de la soberanía popular, ${ }^{2}$ un decidido partidario de la concepción formalista de la ley o positivismo jurídico, ${ }^{3}$ o incluso, si no un antecedente, por lo menos alguien que contribuyó significativamente a la moderna teoría de la división de poderes. ${ }^{4}$ Cierto es que tales atribuciones fueron en la misma medida cuestionadas en vista de la necesidad de insertar adecuadamente la comprensión del pensa-

- Agradezco las observaciones y sugerencias de los profesores Francisco C. Bertelloni y Esteban F. Mizrahi.

* Universidade de Buenos Aires.

1 Cf. Battaglia, F., Marsilio de Padova e la filosofia politica nel medioevo. Firenze, 1928, p. 55-59; "Modernità di Marsilio da Padova" en Marsilio da Padova. Studi raccolti nel VI centenario della morte, Padova, 1942, p. 104.

Cf. Gewirth, A., Marsilius of Padua and Medieval Political Philosophy. New York, 1951.

3 Cf. Gewirth, A., op. cit., p. 134-7.

4 Cf. Crosa, E., "Marsilio da Padova e il principio della separazione dei poteri" en Marsilio da Padova. Studi raccolti nel VI centenario della morte, Padova, 1942, p. 81-95. 
miento político de Marsilio dentro del marco histórico y social en el cual surgió. De dichas consideraciones resultó la imagen de un Marsilio mucho menos "moderno", y más familiar a los rasgos generales de la tradición política medieval que le precede. ${ }^{5}$ Pero aún después de las debidas revisiones sobre la dependencia de Marsilio respecto del contexto histórico y doctrinario de su época, y tras el ocaso del debate sobre la "modernidad" de Marsilio, sigue quedando la impresión de que efectivamente existen algunos elementos de la filosofía política marsiliana que lo distancian de la tradición clásica medieval, y que más bien prefiguran o anticipan conceptos que adquirirán pleno desarrollo en la edad moderna. Entre ellos se cuenta, especialmente, la posible presencia de una concepción contractualista del origen de la sociedad - en el sentido de la moderna teoría del Contrato social -, en oposición a la tradición clásica de cuño aristotélico que concibe al hombre como un ser sociable y político por naturaleza.

En la primera sección de su principal obra, el Defensor de la paz, Marsilio desarrolla, con motivo de su peculiar objetivo - la refutación de las doctrinas teocráticas papales -, todo un programa de filosofía política que pretende inspirarse en la Politica de Aristóteles, y que incluye una explicación de la causas de la comunidad política o civitas, y de sus partes. Los hombres tienen por naturaleza un impulso o apetencia originaria por la suficiencia de la vida; pero no contando inicialmente con los medios necesarios para procurársela, se vieron obligados a forjarse, con su razón, diversos géneros de artes y oficios con los que satisfacer sus necesidades. Como el desarrollo de tales artes y disciplinas implica la comunicación y participación recíproca de muchos individuos, los hombres se "congregaron" en la comunidad civil o civitas, la comunidad acabada o perfecta, que posee en sí el término de la autosuficiencia. ${ }^{6}$ Con frecuencia Marsilio alude al hecho de que los hombres "convinieron" en la comunidad civil, en procura de la obtener la suficiencia de la vida. Y en diversas partes de su obra se refiere al "establecimiento" de la civitas en términos de una "institución racional", lo que parecería significar que en la constitución de la sociedad política han intervenido decisivamente la razón y la voluntad humanas.

De expresiones como éstas y otras similares surgió en algunos intérpretes y comentadores la convicción de que Marsilio se inscribe, a su modo, en la línea de los pensadores que remiten el origen de la sociedad política a un acto fundante y voluntario por el cual se constituye la sociedad misma. Así por ejemplo, en la destacada obra del jurista alemán Otto von Gierke, Marsilio aparece como uno más en la lista de aquellos que "han remitido todo vínculo político a la libre auto-asociación de los individuos. ${ }^{17}$ Con este punto de partida, la versión contractualista de

5 Cf. Passerin d'Entrèves, "Rileggendo il Defensor pacis" en Riv. stor. ital. 51 (1934) p. 1-37, y fundamentalmente, la gran obra de De Lagarde, G., La naissance de l'esprit lä̈que au déclin du moyen age II: Marsile de Padoue ou le premier théoricien de l'Etat laíque. $2^{a}$ ed. Paris, 1948.

6 Cf. DP I iv, 2, 3, 5. Cito por sección, capitulo y número de párrafo, y a continuación - entre corchetes - página y número de líneas de la edición de Previté-Orton, C.W., The Defensor Pacis of Marsilius of Padua, Cambridge, 1928.

7 Cf. Gierke, O., Johannes Althusius und die Entwicklung der naturrechtlichen Staatstheorien, Breslau, 1902, p. 96, n. 28 (citado en Grignaschi, M., "Le rôle de l'aristotélisme dans le Defensor pacis de Marsile de Padoue" en Rev. Hist. Phil. relig. 35 (1955) p. 302, n. 3). 
Marsilio más célebre ha sido la de Grignaschi, para quien, aún reconociendo la obvia incompatibilidad con el hecho de que Marsilio reconozca su principal fuente en Aristóteles, y sin perjuicio del naturalismo al cual de todos modos persiste en adscribir, cabría finalmente reconocer que la "sociedad es, para el Doctor Paduano, en primer lugar, una libre creación de voluntades individuales" ${ }^{8}$ En la misma línea, recientemente el historiador alemán Jürgen Miethke no parece encontrar mayores dificultades en relacionar a Marsilio con el contractualismo moderno: en su opinión, "para Marsilio la socialización del hombre no resulta del hecho de que el hombre, como animal sociale, tienda a la vida comunitaria. El hombre es el único ser incapaz de hacer frente a los obstáculos [...] representados por las inclemencias del tiempo y la lucha por la vida. Por ello constituye una sociedad con sus semejantes. [...] La sociedad se define, pues, en función de la necesidad que tiene el hombre de mantener la vida suficiente. Es, en consecuencia, la percepción de esa necesidad el presupuesto que conduce al acto voluntario mediante el que se constituye la sociedad. Ese acto es ante todo un acto voluntario; recién secundariamente se trata de un acto natural. Aqui se anuncian las teorias contractualistas modernas." ${ }^{\prime 9}$

Sin embargo, cabe señalar que con el mismo énfasis se ha negado toda posibilidad de atribuir cualquier tipo de contractualismo a la figura de Marsilio. Según Battaglia, Marsilio no habla en ningún momento de un contrato originario mediante el cual se abandone un hipotético "estado de naturaleza" por un nuevo "estado social"; tampoco habría rastro alguno de pactum unionis o de pactum subiectionis. En definitiva, "para Marsilio el Estado tiene un origen natural y no contractual", y surge de una exigencia primaria, y "fuera del arbitrio humano. ${ }^{110}$ Pero aún fuera de la órbita de los comentadores italianos que reivindican la profundidad y vigencia del pensamiento de Marsilio, la noción de contractualismo no alcanzó mayor fortuna. Para un duro crítico del valor filosófico de la obra de Marsilio como De Lagarde, el paduano "despoja al Estado de todo substratum metafísico y moral y lo reduce a una mera asociación de individuos sin mayor preocupación que vivir el uno al lado del otro"; y sin embargo, para el historiador francés no es posible llevar esta idea demasiado lejos: "sería en vano buscar en Marsilio un verdadero anuncio del Contrato social". ${ }^{11}$ Similares conclusiones encontramos en Quillet: del Contrato social "no hay trazo alguno" en el Defensor pacis: el término mismo debería ser considerado, desde la perspectiva marsiliana, como completamente anacrónico. ${ }^{12}$

El propósito del presente trabajo es delimitar en qué sentido y con qué alcance puede defenderse la tesis que atribuye un contractualismo de tipo moderno a la filosofía política de Marsilio de Padua, para lo cual procederemos del siguiente modo: (I) en primer lugar, pasaremos revista brevemente a los principales textos del Defensor pacis que puedan servir de base o que han sido utilizados por diversos intérpretes para corroborar los supuestos rasgos contractualistas de Marsilio; (II) a

8 Cf. Grignaschi, M., "Le rôle de l'aristotélisme..." p. 308.

9 Miethke, J., Las ideas politicas en la Edad Media (trad. F. Bertelloni) Bs. As., Biblos, 1993, p. 150.

10

11

12 Cf. Quillet, J., La philosophie politique de Marsile de Padoue, Paris, 1970, p. 81. 
continuación propondremos distinguir dentro del concepto general de contractualismo una serie de nociones que suelen incluirse en él, y cuyo análisis puede contribuir a precisar sobre qué base y en qué sentidos se puede calificar a una doctrina política como "contractualista"; por último, (III) trataremos de aplicar la clasificación postulada en (II) al caso particular de Marsilio, para indagar si efectivamente las nociones así delimitadas pueden rastrearse en los principales momentos de la argumentación filosófico-política del Defensor pacis.

\section{I}

Un examen atento del texto del Defensor pacis nos da la siguiente lista de los principales pasajes relevantes para nuestro propósito, no tanto por lo concluyente que puedan resultar en sí mismos, cuanto por la utilización que la crítica ha hecho de los mismos. Los enumeraremos según su orden de aparición en la obra, atendiendo siempre especialmente al contexto en el que se encuentran:

[1] "Es pues, la ciudad, según Aristóteles, libro primero de la Política, capitulo 1ª, la comunidad acabada que tiene el término de la autosuficiencia, lo que significa, en consecuencia, que ha sido hecha (facta) ciertamente con vistas al vivir, pero que existe con vistas al vivir bien." ${ }^{13}$

Este texto enuncia, tal como puede apreciarse, la definición del término "civitas", que Marsilio toma de la Política aristotélica, y que dicho sea de paso, revela ya, a juicio de Marsilio, la causa final de la misma: el "vivir bien" representa el fin con vistas al cual ha sido instituida la ciudad, y la necesidad que determina todo lo que los hombres realizan en ella. Ahora bien, tomada en sí misma, difícilmente podría pensarse que la definición aristotélica pudiera servir de base para una concepción contractualista del Estado; sin embargo, si es cierto que Marsilio adhiere a una teoría del contrato social, ¿cómo pudo haberla encontrado en el texto aristotélico en el que confiesa inspirarse? En tal sentido se ha argüido que cierta ambigüedad en la traducción latina pudo haber servido de base para proyectar indebidamente en el texto aristotélico una concepción decididamente extraña. Basta con que el término "facta" en la expresión "facta quidem igitur vivendi gratia" sea tomado como un participio pasado del verbo facere (hacer) en lugar de un participio del verbo fieri (hacerse, nacer, resultar), para entender que la ciudad ha sido "instituida" o establecida con vistas al vivir bien. Y en efecto, unas líneas más adelante el "vivir bien" aludido se convierte en el fin por el cual la ciudad ha sido "instituida": "est enim [...] cuius gratia civitas instituta est." ${ }^{\text {14 }}$ Asi es como Grignaschi entiende esta "institución" de la civitas lisa y llanamente como la "creación de la Ciudad por un acto jurídico, por un Contrato Social." ${ }^{15}$

13 "Est autem civitas secundum Aristotelem I Pol. capitulo 10: perfecta communitas omnem habens terminum per-se-sufficientiae, ut consequens est dicere, facta quidem igitur vivendi gratia, existens autem gratia bene vivendi." (DP. I iv, 1 [PO 11, 21-24]).

14 $D P$ I iv, 2 [PO 12, 7].

15 Cf. Grignaschi, M., "Le rôle de l'aristotélisme..." p. 311. 
[2] "Por tanto, los hombres se congregaron con vistas a vivir de modo suficiente, poder procurarse las cosas necesarias enumeradas anteriormente, y compartirlas mutuamente. Esta congregación (congregatio) así acabada, y que posee el término de la autosuficiencia, es denominada 'ciudad'. ${ }^{16}$

El pasaje sintetiza y concluye una demostración general acerca de la causa de la ciudad y de sus partes. El hombre se halla por su naturaleza en una condición inicial de indigencia en comparación con el resto de los seres vivientes - nace desnudo, sin abrigo, indefenso, etc. -; por lo cual necesita de diversos géneros de artes y oficios - agricultura, industrias artesanales, milicia, etc. - con que suplir dichas deficiencias. Como ello a su vez implica el concurso y la asistencia reciproca de muchos individuos, los hombres se congregaron a tal fin: la ciudad es así el resultado de tal asociación, y es definida explícitamente como una congregatio. El pasaje bien podría ser entendido en clave contractualista: ciertas necesidades excepcionales y específicas determinan que los hombres busquen asociarse para constituir la comunidad civil: ésta no parece representar la condición originaria o esencial del hombre, sino un medio al que se ha arribado para conseguir la satisfacción de las necesidades de la vida. Por lo demás, dicho proceso ha implicado la intervención de la razón humana - que crea las artes y oficios - y en igual medida, de la voluntad y el arbitrio de los hombres.

[3] "En efecto, los hombres convinieron en la comunidad civil para conseguir beneficio, es decir, la suficiencia de la vida, y apartar lo contrario. ${ }^{.17}$

En un contexto diferente, Marsilio se ocupa de demostrar una de sus principales tesis: que la autoridad legislativa, la autoridad de "dar e instituir las leyes" corresponde a "la totalidad de los ciudadanos o su parte preponderante" (universitas civium aut eius valentior pars). Mediante tres argumentos de estricta forma silogística, Marsilio intentará demostrar esta afirmación, remitiendo a su vez las premisas de estos silcgismos a proposiciones por sí evidentes o ya explicadas anteriormente, o a bien a nuevos prosilogismos que confirman la evidencia del silogismo principal. El pasaje en cuestión viene en apoyo de la premisa mayor del tercero de estos silogismos, según la cual, la totalidad de los ciudadanos ha de ser la que regule la esfera de la acción y la conducta de los hombres. Nuevamente tenemos, entonces, que los hombres han "convenido" en la comunidad civil, siempre por la necesidad de alcanzar la suficiencia de la vida y escapar de lo contrario.

[4] "Pues asi como los hombres al principio convinieron en ordenar la comunidad civil y la ley, estando de acuerdo su parte preponderante en lo que hace a la suficiencia de la vida, y ciertamente no fueron convocados por un individuo o por varios con autoridad coactiva sobre los demás, sino por la persuasión y exhortación de hombres prudentes y elocuentes que la naturaleza produjo con inclinación a ello entre el resto, y [tal como ] con posterioridad tomaron de ellos provecho de sus ejercicios y dirigieron a los otros, de una vez o sucesivamente, hacia la forma de la comunidad perfecta, a la cual los hombres,

16 "Fuerunt igitur homines propter sufficienter vivere congregati, potentes sibi quaerere necessaria numerata pridem, illa sibi communicantes invicem. Haec autem congregatio, sic perfecta et terminum habens per-se-sufficientiae, vocata est civitas..." (DP I iv, 5 [PO 14, 7-11])

17 "Convenerunt homines ad civilem communitatem propter commodum et vitae sufficientiam consequendam et opposita declinandum." (DP I xii, 7 [PO 53, 5-7]) 
inclinados también naturalmente hacia ella, se sometieron fácilmente por obra de quienes los persuadian..."

Ya en el contexto de la segunda dictio, de lo que se trata ahora es de la correspondiente autoridad y modo de convocatoria al Concilio o asamblea general de los creyentes, que en la época de la iglesia primitiva se reunía con facilidad por la convocatoria de algún apóstol inspirado. En una larga prótasis comparativa, Marsilio explica cómo los hombres "convinieron" en la comunidad civil, bajo la persuasión de ciertos hombres naturalmente dotados de la elocuencia necesaria como para inducir al resto a someterse con facilidad al régimen más perfecto dentro de las diversas formas de comunidades, a saber, la comunidad civil o civitas. A pesar de las referencias a la tendencia natural de los hombres hacia la comunidad civil, y el importante papel asignado a las condiciones naturales de aquellos hombres destacados, el pasaje representa cabalmente - a juicio de Grignaschi - la reunión espontánea, en un momento histórico o lógico inicial y fundante, de hombres libres e iguales entre si - no congregados por un "poder coactivo" -, con el objeto de "constituir algo nuevo", de fundar una sociedad que se ha considerado como necesaria e imprescindible para la suficiencia de la vida. Así concluye Grignaschi que la teoría del Contrato social "no se podría enunciar en términos más categóricos"19

\section{II}

Es evidente que una respuesta clarificadora de la cuestión que nos ocupa depende a su vez de la precisión con que se determine lo que se quiere significar con el término "contractualismo". En efecto, bajo tal concepto suele entenderse un conjunto de nociones diversas, algunas de ellas ciertamente relacionadas e implicadas mutuamente, pero que resulta conveniente delimitar:

(i) Cuando se habla de contractualismo suele hacerse referencia a una concepción según la cual la condición social del hombre no es su condición originaria y esencial: en ocasiones ello se entiende en el sentido de que antes de su condición social se verificó - o puede conjeturarse que se dio - un estado individual del hombre, sea éste preferible o peor que el estado posterior. La mayoría de las veces esta afirmación reviste un carácter meramente hipotético, limitada a la función de una postulación teórica, lo que no evita que se busque para ella algún tipo de corroboración empírica o de sustento argumentativo. A esta concepción, que afirma la existencia de un originario modo de vida individual del hombre que le es natural, se le opone aquella según la cual el hombre es un "ser sociable por naturaleza", es decir, que corresponde a la esencia y naturaleza del hombre el vivir siempre en sociedad con sus semejantes; el hombre

18 "Sicut enim ad civilem communitatem et legem ordinandam convenerunt homines a principio, ipsorum valentiori parte concordante in hiis quae sunt ad vitae sufficientiam, non quidem vocati per singularem hominem aut per plures aliquos habentes auctoritatem coactivam in reliquos, sed suasione seu exhortatione prudentum et facundorum virorum, quos natura inter alios produxit inclinatos ad hoc, ex se postmodum proficientes suis exercitiis et alios dirigentes successive vel simul ad formam communitatis perfectae, ad quam etiam homines naturaliter inclinati obtemperavenunt suadentibus facile [...]; sic proportionaliter..." (DP II xxii, 15 [PO 353, 10-19])

19 Cf. Grignaschi, M., "Le rôle de l'aristotélisme..." p. 307-8. 
es, desde esta perspectiva, un zóon politikón, y quien vive fuera de la sociedad humana o es una bestia o es "más que un hombre" - un dios - $-{ }^{.20}$

(ii) En otro sentido, suele invocarse el nombre de contractualismo para aquella concepción que pone el énfasis en la sociedad política como un resultado del arbitrio y la razón humanos, algo de índole enteramente artificial, cuya existencia se debe más bien a una convención que a la "naturaleza". Esta concepción suele contraponerse a aquella según la cual el Estado mismo es "por naturaleza", en el marco, por ejemplo, de la clásica antítesis griega entre nómos y physis. En términos aristotélicos, ello significa que la "comunidad perfecta" o pólis representa el resultado y el término de la evolución natural de las "comunidades primitivas" - la familia y la aldea -, para las cuales constituye su télos o fin natural, y por ello se dice que la pólis "se cuenta entre las cosas que son por naturaleza" ${ }^{21}$

(iii) Más propiamente, se designa con el nombre de contractualismo - en el sentido del clásico contractualismo moderno - a aquella concepción según la cual la sociedad política se constituye en un contrato o pacto entre individuos autónomos y libres, que por medio de tal contrato se comprometen a vivir en sociedad; en cuanto a su fundación, esto es, en cuanto al fundamento de su constitución y la base de su legitimidad, los individuos "preceden" a la sociedad política: ésta es más bien una resultante de aquéllos. Aquí resulta más complejo determinar qué clase de teorías políticas puede contraponerse a esta noción: a la concepción de la sociedad fundada en un contrato efectuado por individuos autónomos y libres puede oponerse diversas formas de concebir el origen y los fundamentos de la sociedad política, ya sea teorías organicistas, ya sea teorías fundadas en la eticidad y las costumbres, o basadas en el mero predominio de la fuerza, etc.

\section{III}

Si aplicamos ahora estas delimitaciones al caso de Marsilio, correspondería que nos formulásemos las siguientes preguntas: (i) ¿puede decirse que efectivamente existió, según la concepción marsiliana del origen de la sociedad, un momento en que el hombre tuvo una existencia aislada e individual?, (ii) ¿en qué sentido y hasta qué punto puede decirse que para Marsilio la sociedad política tiene su fundamento en la naturaleza o que es un resultado de la voluntad humana?, y finalmente (iii) ¿remite o no Marsilio el fundamento de la sociedad política a un contrato en el que libremente convienen individuos autónomos que así instituyen la sociabilidad humana y sus vinculos políticos?

\section{(i) El estado individual del hombre}

Es importante advertir que al momento de trazar la explicación del origen y las causas de la civitas Marsilio parece expresarse en términos que combinan y articulan la perspectiva teórica o especulativa con una descripción de tipo histórica 
que pretende dar cuenta de cómo han sucedido efectivamente los acontecimientos. La explicación de la causa final de las civitas y de sus partes es formulada, al mismo tiempo, como una descripción del proceso histórico que culminó con la aparición de la civitas. Impulsados en su apetencia por la vida suficiente, los hombres buscaron suplir las carencias y desventajas de su indigencia inicial desarrollando diversos géneros de artes y oficios. Pero para ello se requirió del concurso y la asistencia recíproca de una pluralidad de hombres. Persiguiendo, pues, el objetivo de la suficiencia de la vida es que los hombres se "congregaron" para constituir la comunidad perfecta o acabada que es la civitas. La pregunta es, pues, ¿hubo un momento "anterior" a dicha "congregación" en el cual los hombres efectivamente vivieron en un modo de existencia individual? ¿Existió alguna época en la cual los hombres no necesitaron suplir sus deficiencias con el recurso a la ayuda mutua, y vivieron, por tanto, separados y aislados entre sí?

Una primera aproximación a la respuesta marsiliana acerca de la cuestión del origen de la comunidad civil nos da una respuesta claramente negativa. En su descripción histórica del proceso que condujo a la formación de la civitas Marsilio intenta adecuarse a la doctrina aristotélica de la evolución de las comunidades primitivas en la comunidad perfecta o ciudad: los antecedentes de esta comunidad son la casa (domus) - ámbito en el que reside la familia - y la aldea o villa (vicus), comunidad primitiva que aún no tiene aquella perfección en la autosuficiencia que caracteriza a la ciudad. Para estas comunidades antecedentes, la ciudad constituye su término y fin natural. Marsilio se refiere a esta evolución como un proceso histórico analizado desde una perspectiva empirica: "según las diversas épocas y territorios" las comunidades comenzaron "a partir de lo pequeño" (ex parvo):

"La primera y mínima asociación humana, de la cual también provinieron las demás, fue la de varón y mujer [...]. A partir de ella, por cierto, se propagaron los hombres, los cuales habitaron primero en una única casa (domus). Al producirse asociaciones más amplias, tanta fue la propagación de los hombres, que no les bastó con una única casa, sino que convino construir varias, cuya pluralidad es denominada aldea o villa (vicus seu vicinia). Y esta fue la primera comunidad....22

Según esto, los antecedentes de la civitas están dados por formas de comunidad que implican un diverso grado de sociabilidad y convivencia. "Antes" de que se desarrollase la civitas, los hombres ya convivian en la aldea o vicus, una comunidad primitiva que, si bien no representa el más alto grado en el desarrollo de los tipos de comunidades, implica ya, para Marsilio, cierto tipo de regulación de la conducta de los hombres por parte de un individuo destacado - un anciano venerable o respetado -, el cual administra justicia según un esbozo de ley o norma cuasi-natural ${ }^{23}$ De suerte que el momento precedente de la constitución de la civitas presupone no sólo un modo de vida social del hombre, sino una convivencia regulada ya en cierta forma por algún principio general de justicia y equidad, aunque no alcance el grado de una acción de gobierno ejercida por un poder instituido y conforme a un sistema legal establecido. Y aún mucho antes, en primer término, el punto de partida de toda ulterior asociación humana lo constituye la familia, o

22 DP I iii, 3 [PO 9, 20-10, 2].

23 Cf. DP I iii, 4 [PO 10, 14-17]. 
como dice Marsilio, "la unión entre varón y mujer": tal unión implica, sin duda, cierto tipo de sociabilidad, - de hecho, la mínima posible - y por si fuera poco, de carácter natural. La familia constituye, por cierto, un vínculo social de carácter permanente y estable, de origen natural, y sin ninguna connotación contractual ${ }^{24} \mathrm{La}$ observación no carece de importancia, dado que la evidencia del dato de la sociabilidad natural de la familia no necesariamente ha forzado a todo pensador contractualista a admitirla como negación de un estado individual del hombre. ${ }^{25}$

Con todo, debe reconocerse un único resquicio en el que puede rastrearse, si no una explícita afirmación de Marsilio acerca de un modo de vida individual del hombre, al menos una reserva respecto de que necesariamente el hombre haya vivido siempre en sociedad y necesitado de sus semejantes para bastarse. Es característico de la especulación antropológica medieval el que no se agote en el estado presente del hombre, sino que se extienda también a la condición originaria del hombre en el paraíso. En un notable retroceso al locus agustiniano del Estado como consecuencia del pecado original, Marsilio concede que en el estado paradisíaco, Adán contaba fácilmente con las oportunidades y satisfacciones que la naturaleza le proporcionaba "sin pena ni esfuerzo", de suerte que, si hubiese permanecido en dicho estado, no hubiesen sido necesarias para él ni para su posteridad la institución y distinción de los oficios civiles - es decir, la creación de las respectivas partes de la ciudad $-{ }^{26}$ La presente condición social del hombre - requerida por su indigencia - es, en consecuencia, un resultado de la caída. Sin embargo, aparte de que estas afirmaciones no son más que una interpretación teológica de los hechos de la experiencia actual, que no modifican su contenido, tampoco superan el grado de una mera hipótesis probable, consideradas desde el punto de vista del conocimiento científico y racionalmente demostrativo: en efecto, se trata de verdades accesibles únicamente mediante la revelación, y que Marsilio expresamente deja de lado - o intenta dejar - en su investigación.

\section{(ii) Naturalidad o artificialidad de la sociedad política}

La calificación de una cierta doctrina política como contractualista se determina a veces, con mayor o menor propiedad, en los términos de la antítesis naturaleza-razón o naturaleza-voluntad humana. La fundación de la sociedad por el contrato social suele entenderse en el sentido de que no es un "producto natural", sino una obra de la razón humana, instituida por un acto libre y voluntario. Ahora bien, a la hora de determinar la posición de Marsilio dentro de esta alternativa, la respuesta es compleja, y quiebra en cierto sentido la validez de la opción: la sociedad política, para Marsilio, no tiene un carácter ni absolutamente artificial, ni meramente natural.

24 Cf. Quillet, J., op. cit., p. 80.

25 Rousseau, por ejemplo, sostiene - en contra de Locke - que en el "estado de naturaleza" la unión entre macho y hembra tiene un carácter ocasional y perentorio. Cf. el Discurso sobre el origen de la desigualdad entre los hombres (Rousseau, J., Del Contrato social. Discursos... (Trad. M. Armiño) $2^{2}$ ed., Madrid, Alianza, 1982, p. 226); la unión de los hijos con sus padres también se limita al tiempo necesario para garantizar su conservación: cf. Contrato social I cap. 2 (op. cit. p. 11).

Cf. DP I vi, 1 [PO 22, 1-8]. 
Para reconocer el fundamento natural de la sociedad en Marsilio, basta con recordar, en primer término, el "principio autoevidente" y fundamental del cual pretende derivar todas las conclusiones positivas de la primera sección de su Defensor pacis. En efecto, Marsilio se compromete a desarrollar dicha parte de la obra con una metodología estrictamente científica, desde ya según el canon aristotélico de las ciencias teóricas, esto es, por demostración racional y a partir de principios naturalmente evidentes y accesibles a todo entendimiento humano ${ }^{27} \mathrm{Y}$ asi es como el principio fundamental de todo lo que habrá de demostrarse sostiene:

\footnotetext{
"todos los hombres, no corrompidos o impedidos de otra manera, apetecen naturalmente la vida suficiente, y de allí también rehuyen y se apartan de lo nocivo. ${ }^{28}$
}

De acuerdo con este principio, pues, en todos los hombres - salvo casos excepcionalmente "patológicos" u "orbati" - reside una inclinación o apetencia, un impulso originario de carácter natural, cuyo objeto es la vida suficiente: por efecto de esta inclinación los hombres tienden naturalmente a buscar los medios y recursos que les permitan bastarse en lo que hace a las necesidades de la vida. Que esta tendencia tiene una índole natural queda suficientemente asegurado ni bien se repara en que Marsilio extiende el alcance de este principio no sólo al hombre, sino a todo el género animal. ${ }^{29}$ Como consecuencia de esa inclinación los hombres inventaron diversas artes y oficios cuya perfección en desarrollo y variedad se lograron sólo en la comunidad acabada o ciudad: más aún, Marsilio se refiere a la perfección o el término en el grado de diferenciación y desarrollo de estas artes y oficios como si fuese equivalente a la consumación de la perfecta distinción y asignación de las respectivas partes u oficios que caracteriza a la comunidad perfecta o ciu$\operatorname{dad}^{30}$ Por tanto, si es cierto que dicha sociedad no fue la forma originaria y primitiva de comunidad - en todo caso, le precedieron la casa y la aldea -, no es menos cierto que la constitución misma de la comunidad política obedece, en última instancia, a un proceso que reconoce como su motor primario y factor desencadenante una inclinación natural humana: la apetencia originaria por la vida suficiente.

Pero por lo dicho resulta al mismo tiempo evidente que el surgimiento de la $\mathrm{ci}$ vitas implica, en la misma medida, la intervención de la razón humana, ante todo, en la elaboración de aquellas artes y disciplinas mencionadas. Esta acción proveniente de un agente causal de índole racional, como lo es el arte, significa un aporte específicamente humano a la obra inicial de la naturaleza. Marsilio lo explica claramente: como el hombre no recibió completa e inicialmente de la naturaleza todos los recursos imprescindibles para la vida

"fue necesario que el hombre formase, más allá de las causas naturales y por medio de la razón, algunas cosas con que completar la eficiencia y conservación de sus acciones y pasiones relativas al cuerpo y al alma.. ${ }^{31}$

27

28

29

30

31 
El surgimiento y la conformación de la civitas resulta así de la confluencia de dos agentes causales de índole diversa: el uno, natural - la apetencia por la vida suficiente -, el otro racional - la acción del arte humano -. Pero entre ambos factores no existe solución de continuidad alguna: precisamente a ello viene el principio aristotélico, que Marsilio invoca oportunamente, acerca de que "el arte tiende a completar o perfeccionar lo que la naturaleza no puede hacer por sí misma." ${ }^{132}$ En efecto, la intervención de la razón humana aplicada a la creación de las diversas artes u oficios no hace sino "completar" o "perfeccionar" las condiciones de una naturaleza que, como hemos visto, se presenta inicialmente como deficitaria e indigente. El arte constituye un principio racional extra-natural (ultra causas naturales), pero su acción no tiende sino a dar respuesta o acabamiento a condiciones naturales en las que se halla el hombre: la necesidad de obtener la suficiencia de la vida para la cual, sin embargo, no le alcanza con las solas causas naturales. Justamente por ello Marsilio dirá que la investigación que aquí emprende no se ocupa de las causas meramente naturales del "vivir bien" - que en rigor competen a la ciencia natural, esto es, a la física o la biología -, sino de cómo dichas causas naturales "reciben complemento del arte y la razón por las cuales vive el género humano". ${ }^{33}$ En otras palabras: si el "vivir bien" es la causa final de la ciudad, aquello en vistas de lo cual existe, el objeto de la scientia civilis será explicar precisamente cómo el arte y la razón humanos, al "instituir" la civitas, "dan complemento" a los condicionamientos naturales que impulsan al hombre a vivir en sociedad.

Por tanto, el hecho de que la civitas sea el resultado, como dice Marsilio, de una "institución racional" no significa negar que al mismo tiempo tenga cierta base en la naturaleza, a la cual dicha institución viene precisamente a completar. Pero la articulación entre naturaleza y racionalidad humana no se agota en ello: si es válido el principio de que "el arte completa o perfecciona lo que la naturaleza no logra por sí misma" no menos aplicable había de ser el principio general y más fundamental acerca de que "el arte imita a la naturaleza". Siguiendo las sugerencias de Aristóteles, Marsilio deja ver cierto perfil organicista en su concepción de la sociedad política al recurrir insistentemente a comparaciones y analogías entre la estructura formal de la civitas y la conformación orgánica del ser viviente animado. La ciudad es "como una cierta naturaleza animada o viviente": así como el animal presenta en su disposición natural una composición de partes cuyas funciones y operaciones están ordenadas recíprocamente, y en función del todo al que pertenecen, del mismo modo la ciudad, cuando se halla "bien dispuesta" e instituida según razón, guarda una relación análoga entre el todo y sus partes. ${ }^{34}$ La terminología marsiliana es al respecto bastante precisa: lo que en el orden humano está dado por institución racional - cuyo principio efectivo es el arte - corresponde a lo que en el orden natural presenta una constitución natural - cuyo principio es la naturaleza en cuanto agente causal -. Y esta constitución natural del animal opera como el modelo o paradigma en el que se ha inspirado el arte humano, y al cual "imita" en su institución de la civitas:

32

33

34

Cf. DPI ii, 3 [PO 8, 1-7]. 
"Pero en esto la preocupación humana (humana sollicitudo) ha imitado convenientemente a la naturaleza. Pues la ciudad y sus partes instituidas según razón guardan una analogía con el animal y sus partes formadas perfectamente seguin la naturaleza" ${ }^{135}$

Si la naturaleza es el principio al que se debe la conformación del ser vivo, la razón humana es la que ha diseñado, siguiendo aquel modelo, la estructura constitutiva de la civitas, y obviamente es la voluntad humana la que ha llevado dicho diseño a su realización efectiva. No puede negarse, pues, que es la voluntad humana la que ha instituido la civitas. Dicho sea de paso, la afirmación no carece de importancia para los objetivos políticos que guian la especulación de Marsilio: la legitimidad del poder temporal no admite así ninguna dependencia respecto de una instancia superior sobrenatural que pueda comprometer su independencia y autonomía. Pero si la voluntad humana instituyó la civitas, lo hizo igualmente compelida por una necesidad arraigada en lo más profundo de la naturaleza humana, y conforme a un diseño inspirado en la obra de la naturaleza. Podemos concluir, entonces, que si para Marsilio la sociedad política tiene un fundamento natural, no lo es en el sentido de que "esté dada" naturalmente, como el bosque: por el contrario, se trata efectivamente de un producto de la razón y el arbitrio humanos; mas no por ello deja de ser "natural" en cuanto responde a una inclinación natural del hombre - la apetencia natural por la vida suficiente -, y lo que es más importante, porque en la institución de dicha sociedad la razón humana ha seguido un modelo natural, cual es la constitución orgánica del ser viviente animado.

\section{(iii) La fundación de la sociedad por el Contrato}

Ahora bien, llegados al principal y último punto, si no es posible rastrear en Marsilio la hipótesis de un modo de existencia individual del hombre (i), ni tampoco puede decirse que para Marsilio la sociedad política sea algo de indole absolutamente artificial por oposición a que en alguna medida pueda corresponderle un fundamento natural (ii), ¿cabe al menos la posibilidad de que Marsilio explique, desde una perspectiva teórica, la existencia y la permanencia de la sociedad política como fundadas en un acto de consentimiento por parte de los miembros que la integran, acto de consentimiento que podría entenderse, en última instancia, bajo la forma de un pacto o contrato por el cual se determinan las reglas que constituyen tal tipo de sociedad y por el cual los individuos se someten voluntariamente a dichas reglas?

Por definición, de tal tipo de contrato se desprende que los individuos que pactan son anteriores a la sociedad; si no se trata de una anterioridad temporal o cronológica - en caso de que no se suponga un modo de vida individual del hombre (i) - será una anterioridad "ontológica", en el sentido de que serían los individuos los que constituyen la sociedad política y no a la inversa: dicho de otro modo, si vivimos asociados bajo un régimen político, es porque nosotros, los hombres, lo hemos constituido - por un "acto de nuestra libre voluntad" - y porque consentimos en permanecer en él. 
Pero las mismas implicancias de la analogía biológica a la que apela Marsilio sugieren justamente lo contrario. En el módelo orgánico, las partes no tienen existencia autónoma y sólo subsisten en su integración con el todo al cual pertenecen. El todo orgánico es "anterior" a sus partes, en primer término, según una anterioridad "lógica": en el sentido de que sus partes se definen sólo en relación con él. Pero además, el todo presenta una anterioridad ontológica: a diferencia de otros tipos de compuesto, el todo orgánico se caracteriza precisamente por ser algo más que la mera sumatoria de sus partes componentes, e imposible de obtener por la mera conjunción o el agregado de las mismas. A la inversa, una parte orgánica sólo existe en cuanto está unida al cuerpo vivo, y fuera de él ya ni siquiera es tal, v.gr., la mano separada del cuerpo sólo es mano "equívocamente", como la "mano de piedra" de la estatua. Tal tipo de argumentación es precisamente invocada por Aristóteles, en los comienzos de su Política, para demostrar que la pólis es "anterior" ontológicamente a sus partes componentes, ya sea a las comunidades primitivas como la casa, o bien a los mismos individuos. ${ }^{36}$ De allí que la principal significación que debe extraerse del uso de la analogía biológica con la que se compromete Marsilio es que por ella se transfiere el modelo orgánico a la estructura formal de la civitas. Si en este modelo se ha inspirado la "solicitud humana" al instituir la ciudad y sus partes, las cuales guardan entre sí una proporción semejante a la constitución natural del animal, cabría decir que las partes componentes de la civitas en modo alguno pueden ser anteriores e independientes como para dar origen al todo mismo: en tal sentido, sería imposible hablar de individuos autónomos capaces de fundar el cuerpo social.

Pero una vez más, ¿acaso esta estructura orgánica no ha sido instituida por la razón humana? ¿Existe alguna instancia anterior y fundante a la "generación" de este gran organismo que es la civitas? ¿No podría ser esta instancia justamente la multitud o el conjunto de aquellos individuos que se "congregan" para constituir la comunidad civil? Los extremos a los que Marsilio lleva la comparación entre la ciudad y el ser viviente podrían ofrecer alguna base en tal sentido. De hecho, la anterioridad de la civitas respecto de sus partes, como la del animal respecto de sus órganos, no implica necesariamente una anterioridad temporal o en el orden de la generación: el organismo bien puede desarrollarse, en el proceso de su génesis, a partir de un órgano primario y embrional, del cual van surgiendo luego, por diferenciación progresiva, las distintas partes que habrán de constituirlo. Apelando a los conocimientos de la ciencia natural de su época, Marsilio asimila así la institución de las partes fundamentales de la civitas a la generación del animal:

\footnotetext{
"a partir del alma de la totalidad de los ciudadanos o su parte preponderante (ab anima universitatis civium aut eius valentioris partis) se forma - y debe formarse - primeramente una parte única análoga al corazón, en la cual establece cierta virtud o forma, junto con la potencia activa de instituir las restantes partes de la ciudad. $Y$ aquella parte es el principado, cuya virtud de causalidad universal es la ley, y cuya potencia activa es la autoridad de juzgar, prescribir y ejecutar las sentencias de los asuntos de justicia y utilidad en la ciudad..$^{\text {"I? }}$
}

DPI Xv, 6 [PO 70, 7-14] 
Como vemos, la analogía biológica se aplica ahora a la compleja relación de fundamentación entre las instancias principales de la civitas. Dentro de la vasta explicación de las causas de las partes de la ciudad que tiene lugar en la primera dictio del Defensor pacis, desarrollada según la clasificación aristotélica de los cuatro sentidos de causa, tiene su lugar la explicación por la causa eficiente, la cual concluye remitiendo la causa eficiente de las respectivas partes de la ciudad a una pars principans o parte gobernante: ésta es que es quien las instituye y preserva su buena disposición y ordenación recíproca - la paz de la civitas -; y a su vez, esta parte principal o gobernante tiene por causa eficiente al "legislador humano", quien, como su propio nombre lo indica, no sólo designa la parte gobernante, sino que además crea la "forma" o regla de justicia conforme a la cual ésta ha de desempeñar su tarea. ${ }^{38}$

No hace falta destacar que la figura marsiliana del "legislador humano", identificada finalmente con la "totalidad de los ciudadanos o su parte preponderante" (universitas civium aut eius valentior pars) es, en la especulación teórico-política de Marsilio, la instancia fundante de toda autoridad politica de orden temporal, y constituye en tal medida uno de los núcleos esenciales de la filosofía política de Marsilio. ${ }^{39}$ En efecto, la universitas civium es la suprema auctoritas legislativa, la única capaz de promulgar las mejores leyes y de otorgarles carácter obligatorio; al tiempo que es quien instituye la pars principans o el órgano ejecutivo-judicial de gobierno de la ciudad, en quien delega la tarea de regular la conducta de los hombres de acuerdo con las leyes y a quien inviste con el "poder coactivo" de aplicarlas y ejecutarlas. Quizá podría buscarse en esta totalidad o "multitud" de los ciudadanos - como Marsilio también la llama ${ }^{40}$ - aquella suerte de "congregación" o reunión de individuos por la cual se instituyen los poderes fundamentales de la sociedad política, la estructura orgánica que lo conforma e incluso las normas legales que lo definen. Sin embargo - y este es a nuestro entender el punto fundamental -, no parece haber, en Marsilio, mención de pacto o contrato alguno por el cual se instituya la universitas misma en cuanto tal: dicho de otro modo, no hay ningún pactum unionis por el cual se establezca, desde un momento lógico anterior dado por individuos independientes entre sí y en condiciones de contratar, la constitución de dicha corporación; y éste debería ser el principal requisito y condición suficiente para admitir la presencia en Marsilio de una concepción contractualista de indole moderna.

Ciertamente podría replicarse que, si bien es cierto que la tendencia organicista representa una antitesis de la orientación contractualista, ello no obsta para ad-

38

A los fines de nuestro trabajo, es suficiente con que se admita la importancia especulativa de la "totalidad de los ciudadanos" como fundamento teórico de la legitimidad del poder humano, con independencia del significado que pueda tener la alusión a la "parte preponderante" (valentior pars), y en general, con prescindencia del alcance del presunto "republicanismo" de Marsilio, o de su adhesión a una teonia de la "soberania popular"; cuestiones todas demasiado polémicas y arduas como para pretender definirlas aquí. Aun aceptando que Marsilio haya apelado, bajo influencia "romanista", a la figura del pueblo como una "pantalla" de legitimación del poder imperial (cf. por ejemplo De Lagarde, G., op. cit., II, p. 184-194), creemos que ello no afecta a las conclusiones del presente artículo.

40 Cf. DP I xii, 5 [PO 50, 23; 51, 10; 51, 22]; xii, 6 [PO 52, 21], etc. 
mitir la presencia de ciertos "elementos contractuales" en doctrinas y autores medievales o pre-modernos que se reconocen finalmente como organicistas. ${ }^{41} \mathrm{Si}$ este fuera el caso de Marsilio, su pertenencia al contractualismo, en todo caso, debería ser matizada convenientemente, con el fin de distinguirla del contractualismo moderno. Sin embargo, el hecho es que no hay en Marsilio ninguna fundamentación de la constitución de la sociedad misma ni de la legitimidad del poder político en cualquier clase de pacto, sea "de asociación" o "de sujeción". La instancia teórica en la que se fundamenta la legitimidad de toda autoridad y poder políticos de orden humano es, como hemos visto, la universitas civium: en tal sentido es "anterior" - en cuanto principio o fundamento - a las instancias que de ella se derivan: la fuerza de obligatoriedad de la ley y el poder político de gobierno. Por tanto, ni ella misma se constituye mediante un contrato o convenio voluntariamente acordado por individuos anteriores a ella - en tal caso, no se trataría de un fundamento último, sino de otra instancia derivada más - ni instituye a las instancias derivadas mediante un pacto de tal índole. Respecto de la ley, Marsilio insiste en que su institución debe corresponderle a la totalidad de los ciudadanos - o su parte preponderante - mediante tres argumentos que dejan ver una vez más sus preferencias finalistas. La universitas civium ha de instituir las leyes: a) por ser "aquel de quien únicamente pueden provenir las mejores leyes" - por hacer las leyes "más justas", esto es, más perfectas en su aspecto material -, b) por hacer las leyes "mejor y más fácilmente observables" - es decir, por hacerlas de tal modo que quede garantizado su cumplimiento -, y c) porque a ella le compete la recta institución de la "esfera de lo actuable" - o sea, por estar vitalmente comprometida en la preservación de los fines a que tienden las leyes.$-^{42}$ Por su parte, en cuanto a la autoridad de gobierno, Marsilio adjudica su institución a la totalidad de los ciudadanos remitiéndose a los mismos argumentos, y además, al hecho de que quien instituye la ley o la "forma" conforme a la cual se ejerce el gobierno ha de ser el mismo que instituya la "materia" o "sujeto" por el cual el gobierno se desenvuelve y actúa. ${ }^{43}$ La universitas civium es, pues, la causa eficiente del poder coactivo que detenta la parte gobernante, la cual actúa como "causa secundaria", "instrumental" o "ejecutoria" de

41 Cf. Bobbio, N, Mateucci, N. (dir.), Diccionario de Política, (trad. cast.) México, 1985, I, p. 415, sub voce "contractualismo".

42 Cf, DP I xii, 5-7 [PO 50, 23-53, 13]. De estos tres argumentos el segundo es ciertamente el que alcanza mayores resonancias modernas, especialmente en el momento en que Marsilio parece fundamentar la competencia legislativa de la universitas civium en su carácter auto-legislativo: invocando a Aristóteles, Marsilio recuerda que la ciudad es "la comunidad de hombres libres", por lo que negar que todos intervengan en la legislación equivale a establecer que unos pocos sean "déspotas" de los demás, con la consecuencia de que éstos se resistirán a la ley y desconocerán su validez. Por el contrario si la ley es "instituida por el examen y el consenso de toda la multitud, cualquier ciudadano la observaria y soportaria fácilmente, incluso la menos conveniente. Dado que a cualquiera le parecerá haberla estatuido para sí, no tendrá reclamo contra ella, sino más bien la tolerará de buen ánimo." (I xii, 6 [PO 52, 20-24], subr. nuestro). Sin embargo, Marsilio no llega a fundamentar la legitimidad de la auctoritas legislativa en el derecho de la universitas a auto-legislarse, sino que simplemente argumenta que, en tales condiciones, las leyes serán "mejor y más fácilmente observadas", y en vista de tal necesidad es que debe asignársele la tarea de instituirlas. 
aquélla. ${ }^{44}$ La fundamentación última que Marsilio da para la legitimidad de la autoridad de gobierno tampoco reposa, por tanto, en alguna clase de "pacto de sujeción", por el cual el conjunto de los ciudadanos consienta en someterse al poder de un soberano. ${ }^{45}$

Si repasamos el itinerario recorrido hasta aqui, podemos observar que no ha quedado en pie prácticamente ninguna de las notas con las que se pueda evocar, relacionar o caracterizar una concepción contractualista moderna: no hallamos en Marsilio ninguna postulación de un hipotético estado individual del hombre en este mundo - más allá de la hipótesis no demostrable del estado inocencia -, ni ninguna concepción que impida admitir que la sociedad política tenga en alguna medida un fundamento natural; por último, nos encontramos con una fundamentación teórica de la legitimidad de la autoridad política humana que no se hace sobre ninguna base de tipo contractual, sino sobre una instancia teórica como la universitas civium. Por el contrario, nos hemos topado con el reconocimiento de asociaciones irreductibles de carácter esencialmente natural, como la familia, o bien con rudimentarias formas de convivencia más abarcadoras como la vicus o aldea; con la explicación de los orígenes de la sociedad política en causas primariamente naturales, como la apetencia por la vida suficiente, y con una fuerte adscripción a un naturalismo organicista que interpreta la constitución de la sociedad política no como un resultado de un pacto establecido con anterioridad entre individuos autónomos, sino sobre la base de la conformación orgánica del ser viviente, en la cual el todo resulta necesariamente anterior a sus partes constitutivas.

Este panorama se complementa adecuadamente, si repararamos en que ninguna de las expresiones y giros de Marsilio que pretendidamente aluden a una teoría del contrato social son decisivas al respecto, ni mucho menos resultan incompatibles con el naturalismo y el organicismo en los claramente se compromete. Por cierto, no escapa a la comprensión de Marsilio el hecho de que la ciudad es un fenómeno histórico e institucional, por lo que bien puede decirse que ha sido creada (facta) por el hombre. ${ }^{46}$ En efecto, la sociedad política comprende un conjunto de vínculos, normas legales y personas jurídicas que ni han surgido de la nada, ni han crecido solas: han sido forjadas por la razón humana, e instituidas por la voluntad de los hombres. Pero esto no ocurrió de la noche a la mañana, sino en un largo proceso de búsqueda, y ensayo. Y no podía ser de otra manera, desde el mismo momento en que no siempre la ciudad ha existido tal y como se la puede contemplar desde la perspectiva histórica de Marsilio: en otras épocas pudo el hombre haber vivido bajo formas de comunidad más primitiva y menos jerarquizadas, de las que Marsilio también intenta dar cuenta a su modo, a saber, en los términos de la sucesión aristotélica de los tres tipos de comunidades: casa, aldea y ciudad. Por ello

\footnotetext{
44 Cf. DPI xv, 4 [PO 68, 19-24].

45 Lo que no significa que Marsilio no repare en la importancia del consenso de los gobernados como caracteristica esencial de los regimenes de gobiemo "temperados" - las formas "justas" de gobiemo aristotélicas - : cf. DP I viii, 2 [PO 28, 13-17].

46 Cf. texto [1], supra, p. 5.
} 
el hecho de que los hombres se hayan "congregado" ${ }^{17}$ en la comunidad civil no significa sino que sus formas de convivencia evolucionaron hasta llegar al término de su desarrollo en la "comunidad perfecta", única en la cual los hombres alcanzan la absoluta autosuficiencia. Los hombres "convinieron"48 así en la comunidad civil, esto es, "se pusieron de acuerdo", llegaron al convencimiento de que tal es la forma más perfecta 0 acabada de comunidad.

Precisamente porque es posible, mediante el razonamiento y el análisis de la experiencia histórica, evaluar las mejores o peores formas de organizar la vida en sociedad es que tiene sentido una investigación especial sobre el particular que no es otra que la ciencia política que Marsilio reconoce y admira en Aristóteles y los demás "filósofos gloriosos", y cuya principal conclusión es justamente la demostración de la necesidad de la comunidad civil. ${ }^{49}$ Por tanto, aunque el "convencimiento" de tal logro por parte del género humano haya sido el resultado de un lento progreso de la razón humana, en algún momento pudo haber habido una contribución significativa de hombres preclaros que ayudaron, con su "elocuencia", a que el resto de los hombres se integrase a dicho proceso y consintiese en someterse a tal régimen de vida. ${ }^{50}$ Ello en modo alguno va en contra de que la ciudad responda, en última instancia, a una "tendencia natural" del hombre. También en Aristóteles sin que por ello pueda ser sospechado de contractualista -, hallamos, por una parte, que la pólis es "por naturaleza", y que los hombres tienden naturalmente a ella, y por la otra, que es objeto de una "institución" incluso por parte de un individuo destacado - posiblemente en alusión a la obra los grandes "legisladores" - : "Es natural en todos la tendencia (hormé) a tal comunidad [sc. la pólis]. Pero el primero que la estableció (ho prôtos systésas) fue causa de los mayores bienes.. ${ }^{51}$

Una de las posibles formulaciones del problema fundamental de toda filosofía política es la pregunta: ¿por qué vivimos en sociedad?, es decir, ¿por qué acatamos un conjunto de normas legales vigentes y nos sometemos a un determinado poder político que las regula? El examen de la respuesta a esta pregunta permite alinear las diferentes posiciones frente al problema. Desde una perspectiva, una posible respuesta es "porque naturalmente vivimos en sociedad", porque no nos bastamos a nosotros mismos, y además porque la perfección de nuestra vida se realiza en la comunicación con los demás. Para organizar, administrar y regular esa vida que tenemos en común hemos delegado nuestro poder en un gobierno, que debe atender a las necesidades y conveniencias que tenemos en común, al bien de todos. Esta es la contribución propia de la tradición clásica antigua y medieval, de la cual Marsilio de Padua en modo alguno queda excluido.

Desde otra perspectiva diferente, la respuesta es, en cambio, "porque cada uno de nosotros, en cuanto hombre libre, tiene un valor irreductible y una serie de derechos propios que no deben ser avasallados, y ante la necesidad de armonizar y

\footnotetext{
47 Cf. texto [2], supra, p. 5-6.

48 Cf. texto [3], supra, p. 6.

49 Cf. DPI iv, [PO 12, 29-31].

50 Cf. texto [4], supra p. 7.

51 Cf. Arist. Pol. I 1, 1253a29-31.
} 
compatibilizar la interacción de los derechos de todos entre sí, y en tal medida, protegerlos y preservarlos, hemos delegado nuestro poder en un gobierno, que debe velar para que nuestras libertades y nuestros derechos queden garantizados. Y esta es la contribución propia de la modernidad que Marsilio de Padua, aún considerado como antecedente o precursor de la modernidad, no ha alcanzado a madurar. El camino ulterior de la especulación filosófico-política ha quedado signado por el respectivo valor acentuado por ambas tradiciones, cuya articulación y complementación se va revelando poco a poco como ineludible. 